\title{
PROMIS Fatigue short forms are reliable and valid in adults with rheumatoid arthritis
}

\author{
Clifton O. Bingham III ${ }^{1 *}$ (D) Anna Kristina Gutierrez ${ }^{2}$, Alessandra Butanis ${ }^{2}$, Vivian P. Bykerk ${ }^{3}$, Jeffrey R. Curtis ${ }^{4}$, \\ Amye Leong ${ }^{5}$, Anne Lyddiatt ${ }^{6}$, W. Benjamin Nowell', Ana Maria Orbai ${ }^{2}$ and Susan J. Bartlett ${ }^{2,8}$
}

\begin{abstract}
Background: Fatigue is prevalent and impactful in rheumatoid arthritis (RA). There is no standardized measure for its assessment nor data concerning the performance of PROMIS-Fatigue short forms (SFs) in people with RA. We evaluated the construct validity of 4-, 7-, and 8-item PROMIS-Fatigue SFs in RA patients across the range of disease activity.

Methods: Adult RA patients were recruited from an online patient community and an observational cohort from three academic medical centers. Measures included PROMIS-Fatigue SFs, other PROMIS measures, and other patient reported outcomes including RAND-36 Vitality, Fatigue NRS, and patient global assessment of disease activity. Other measures from the observational cohort included 28-joint swollen and tender joints, physician global assessment, and the composite RA clinical disease activity index (CDAl).

Results: Two-hundred online participants and 348 participants from the observational cohort were included. PROMIS Fatigue SF scores spanned the measurement continuum and correlated highly with each other (r's $\geq 0.91$ ) and other fatigue measures ( $r$ 's $\geq 0.85$ ). PROMIS-Fatigue SF scores were highly and inversely associated with Physical Function and Participation (r's -0.77 to -0.78 ), and moderately-highly and positively correlated with pain, sleep disturbance, anxiety, and depression (r's 0.60 to 0.75 ). PROMIS-Fatigue SF scores showed dose-response relationships across fatigue severity descriptors and CDAl categories.

Conclusions: These results provide robust evidence supporting the construct validity of the 4, 7, and 8-item PROMISFatigue SFs. They capture fatigue across the spectrum of RA disease activity in diverse groups of individuals and should be considered for use as patient-centered assessments of disease control and treatment efficacy.
\end{abstract}

Keywords: Patient reported outcomes, Fatigue, Rheumatoid arthritis, Validation, PROMIS

\section{Background}

Fatigue in rheumatoid arthritis (RA) is a prevalent symptom that greatly impacts day-to-day function and quality of life $[1,2]$. Fatigue experienced by patients with RA encompasses a broad spectrum, ranging from mild tiredness to an overwhelming, pervasive state of exhaustion that greatly impacts physical, emotional, and social function and quality of life. Higher levels of fatigue often track with other indicators of increasing RA disease activity [3]. Fatigue has been prioritized by RA patients as one of the most important symptoms for which they seek improvement with treatment [4]. Routine measurement of fatigue

\footnotetext{
* Correspondence: cbingha2@jhmi.edu

${ }^{1}$ Johns Hopkins Medicine, Division of Rheumatology, Mason F Lord Center

Tower, 5200 Eastern Ave \#434A, Baltimore, MD 21224, USA

Full list of author information is available at the end of the article
}

has been recommended for use in RA clinical trials, and when assessing remission of disease [5, 6].

Existing patient-reported outcome measures (PROMs) range from single item rating scales to multidimensional assessments, with no consensus on the optimal approach to fatigue assessment [6-8]. Many of the fatigue measures used in RA research (e.g., SF36-vitality, fatigue visual analog scale (VAS), Bristol Rheumatoid Arthritis Fatigue questionnaire (BRAF) have suboptimal psychometric properties, lack precision across the measurement continuum, or are poorly sensitive to change [7]. The NIH-developed Patient Reported Outcomes Measurement Information System (PROMIS ${ }^{\circ}$ ) fatigue measures have been shown to have robust psychometric properties across multiple chronic conditions although minimally studied in RA [9-12]. 
More than 90 items in the PROMIS-Fatigue item bank query the experience and impact of fatigue [9]. Computer-adaptive testing (CAT) using fatigue bank items provides reasonably reliable and valid estimates with efficiency and participant burden. While attractive for use in many settings, CATs require the availability of the internet, computers, or mobile technology (e.g., Smartphones), and algorithms for real-time administration and scoring. Moreover, the use of CATs in international clinical trials would require that the complete item bank has undergone translation and cultural validation into multiple languages. Thus in clinical trials and across health systems, where internet access to support CAT platforms may be limited, the use of fixed-item short forms (SFs) may be preferable to ensure reliable collection of data.

To measure fatigue over the past 7 days in adults, 4-, 7-, and 8- item PROMIS Fatigue SFs are available in English and other languages. Each SF asks about fatigue experience and impact. We administered the $8 \mathrm{a}$ short form which includes the 4 items on fatigue in the Profile-29; the 8-item adds 4 items. The 7-item SF contains different items. We have previously shown that PROMIS Fatigue SF items are easily understood and meaningful to people with RA [13].

There is limited information concerning the performance of PROMIS Fatigue SFs in RA. Here, we evaluate the reliability and validity and compare the performance of the SFs with each other, with legacy measures, and with other indicators of disease activity. We hypothesized PROMIS Fatigue scores would correlate highly with each other and be strongly and positively associated with worsening disease activity indices, pain, function, sleep and mood and reduced social participation.

\section{Methods \\ Participants}

We engaged participants from different locations to evaluate construct validity of PROMIS Fatigue SFs. We partnered with an online arthritis community (CreakyJoints.org) between July and September 2015 inviting them to participate (hereafter referred to as the "online" participants). They completed inflammatory arthritis questions from the Connective Tissue Screening Questionnaire [14] and an RA medication checklist (described elsewhere; (12) to exclude those with a personal or family history of psoriasis or psoriatic arthritis (PsA). The surveys were completed between July-September 2015. We also used the baseline data of 348 RA patients enrolled in an observational trial at academic arthritis centers in Baltimore, MD, New York City, NY, and Birmingham, AL.

\section{Fatigue measures}

PROMIS SFs included the Fatigue $7 \mathrm{a}$ and $8 \mathrm{a}$, Pain Interference 8a, Physical Function 20a, Depression 8a, Participation in Social Roles and Activities 8a, and PROMIS Adult Profile 29 [15], which also queries sleep disturbance and anxiety. The four RAND-36 [16] vitality items were added shortly after data collection began. Everyone rated average fatigue over the past 7 days using 5- and 11-point scales. Clinic patients also described their fatigue ('How would you rate your fatigue': none, mild, moderate, severe). Additional PROs included the patient global assessment of RA disease activity (0-100 NRS).

\section{Other outcomes}

Among clinic patients, swollen and tender joint counts, physician global assessment, laboratory values, and Clinical Disease Activity Index (CDAI) scores from the visit were abstracted from patient charts. CDAI scores combine the patient and physician global assessments and joint counts to provide an index of disease activity; cut points define remission, low, moderate, and high disease activity.

\section{Statistical methods}

We used the PROMIS Assessment Center Scoring Service to obtain item-response theory (IRT)-calculated scores. PROMIS scores are reported on a T-score metric (population mean of 50 and standard deviation of 10), with higher values representing more of the trait measured. We examined score distributions and compared descriptive statistics between clinic and online groups using t-tests or chi square. As participants from the three academic centers had similar characteristics, data were collapsed for subsequent analysis.

To evaluate reliability, we calculated Cronbach's alpha within scales, and intra-class correlation coefficients (ICC; two-way mixed effects model where people were random and measures were fixed) to assess absolute agreement between measures. We used Bland-Altman plots to view the limits of agreement among measures and systematic differences. We considered values of 0.70 and 0.90 as evidence of acceptable group and individual reliability, respectively [17]. Convergent validity with two legacy fatigue measures (Rand Vitality and 10-point fatigue numeric rating scale) was assessed using Pearson's $r$ with correlations $>0.70$ providing evidence of acceptable validity. We used ANOVA and trend tests to compare scores across disease activity groups. To examine floor and ceiling effects, we evaluated the proportion of participants at the lowest and highest scores (as provided in PROMIS Fatigue SF lookup tables); $\geq 15 \%$ of people at either end was considered evidence of an effect [18]. All analyses were performed in SPSS (v25), and a $p<0.05$ was considered statistically significant. 


\section{Results}

\section{Participant characteristics}

Participants were mostly female, white, and middle aged and had lived with RA on average for 14 years, with $13 \%$ having $\mathrm{RA}<2$ years (Table 1). Compared with clinic patients, online participants were significantly younger, more likely to be white and disabled due to their RA, and reported shorter disease duration, more years of education, and more active disease. Across clinical sites, characteristics were similar, except New York participants were more likely to report a higher level of education and urban residence and Birmingham participants reported greater disability due to RA.

\section{Fatigue scores}

SF scores were relatively normally distributed, spanned a wide measurement continuum, and mean scores reflected significantly greater fatigue than the general population (Fig. 1). Scores on the 7a spanned a larger range than $8 \mathrm{a}$ and $4 \mathrm{a}$, and more closely approximated a normal distribution (Table 2). Scores on the other fatigue scales also spanned a wide range. As expected, PROMIS Fatigue SF scores were strongly correlated with each other ( $r$ 's $\geq 0.91$ ) (Table 3 ) and with other fatigue measures ( $r$ 's $\geq 0.85$ ).

There was no evidence of floor or ceiling effects using PROMIS SF lookup tables. On the 7a, 1\% had scores at the lowest (29.4) and highest (83.2) levels, based on PROMIS SF lookup tables. On the $8 \mathrm{a}, 6 \%$ were at the lowest (33.1) and $7 \%$ at the highest (77.7), while on the $4 \mathrm{a} 7 \%$ scores at the lowest (33.7) and 10\% at the highest (75.8), well below the threshold of $15 \%$ for evidence of floor and ceiling effects.

\section{Reliability}

Cronbach's alpha showed evidence of adequate reliability at the individual level for $7 \mathrm{a}(0.96)$ and $8 \mathrm{a}(0.95)$, and at the group level for $4 \mathrm{a}(0.84)$. ICCs between scales for $7 \mathrm{a}$

Table 1 Characteristics of participants

\begin{tabular}{|c|c|c|c|c|c|c|}
\hline \multirow[t]{2}{*}{ Mean (SD) or \% } & \multirow{2}{*}{$\begin{array}{l}\text { All } \\
\text { Clinic } \\
n=348\end{array}$} & \multicolumn{3}{|l|}{ Sites } & \multirow{2}{*}{$\begin{array}{l}\text { Online } \\
n=200\end{array}$} & \multirow[t]{2}{*}{$P$-value } \\
\hline & & $\begin{array}{l}N Y \\
N=82\end{array}$ & $\begin{array}{l}M D \\
N=217\end{array}$ & $\begin{array}{l}\mathrm{AL} \\
N=49\end{array}$ & & \\
\hline Age (years) & $57(14)$ & $56(15)$ & $56(14)$ & $60(10)$ & $51(12)$ & $<.001$ \\
\hline Female (\%) & $81 \%$ & $85 \%$ & $80 \%$ & $78 \%$ & $84 \%$ & .422 \\
\hline \multicolumn{7}{|l|}{$\operatorname{Race}^{\mathrm{a}}(\%)$} \\
\hline American Indian or Alaskan & $3 \%$ & $<1 \%$ & $3 \%$ & - & $4 \%$ & \\
\hline Asian & $4 \%$ & $9 \%$ & $5 \%$ & - & $1 \%$ & \\
\hline Black or African American & $10 \%$ & $11 \%$ & $13 \%$ & $20 \%$ & $4 \%$ & \\
\hline Middle Eastern/North African & - & - & - & - & - & \\
\hline Native Hawaiian/Pacific Islander & $.2 \%$ & - & - & - & $0.5 \%$ & \\
\hline White & $84 \%$ & $71 \%$ & $79 \%$ & $80 \%$ & $95 \%$ & \\
\hline Other & $1 \%$ & $2 \%$ & $2 \%$ & - & - & \\
\hline Declined & $1 \%$ & $6 \%$ & $<1 \%$ & - & - & \\
\hline \multicolumn{7}{|l|}{ Ethnicity } \\
\hline Hispanic & $7 \%$ & $16 \%$ & $4 \%$ & $2 \%$ & $6 \%$ & .714 \\
\hline Education > High school (\%) & $79 \%$ & $91 \%$ & $76 \%$ & $74 \%$ & $93 \%$ & $<.001$ \\
\hline Employment (\%) & & & & & & .011 \\
\hline Full time & $36 \%$ & $44 \%$ & $35 \%$ & $27 \%$ & $32 \%$ & \\
\hline Part time & $8 \%$ & $6 \%$ & $9 \%$ & $6 \%$ & $8 \%$ & \\
\hline Retired & $23 \%$ & $26 \%$ & $25 \%$ & $12 \%$ & $15 \%$ & \\
\hline Disabled due to RA & $22 \%$ & $14 \%$ & $19 \%$ & $49 \%$ & $32 \%$ & \\
\hline Other $^{\mathrm{b}}$ & $11 \%$ & $9 \%$ & $12 \%$ & $6 \%$ & $15 \%$ & \\
\hline Urban & $80 \%$ & $90 \%$ & $76 \%$ & $80 \%$ & $74 \%$ & .098 \\
\hline \multicolumn{7}{|l|}{ RA Characteristics } \\
\hline RA duration (years) & $14(11)$ & $13(12)$ & $13(10)$ & $17(12)$ & $10(10)$ & $<.001$ \\
\hline Patient Global Disease Activity (0-100) & $30(27)$ & $27(23)$ & $32(28)$ & $28(27)$ & $57(23)$ & $<.001$ \\
\hline
\end{tabular}

${ }^{a}$ Multiple categories selected by some individuals. $\wedge$ Between clinic and online samples

${ }^{\mathrm{b}}$ Other includes unemployed, homemaker, students, disabled - not due to RA 


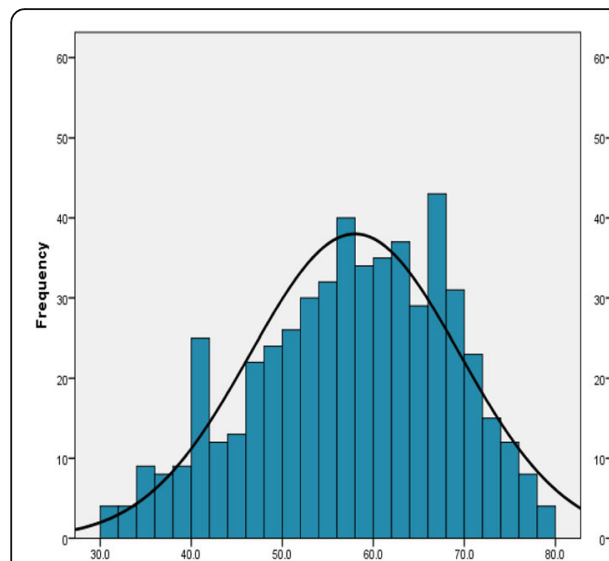

Fatigue 7a

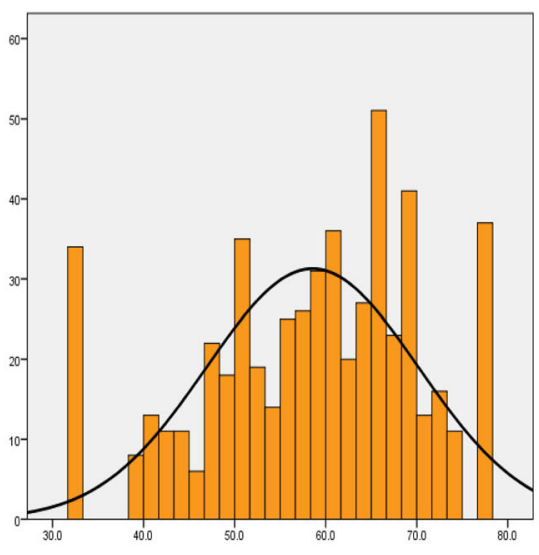

Fatigue $8 \mathrm{a}$

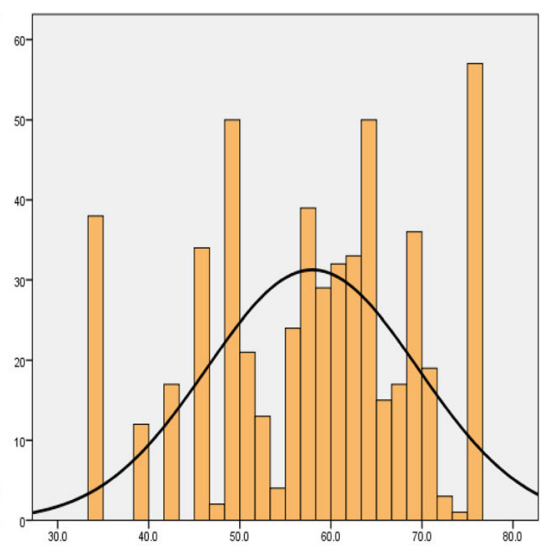

Fatigue 4a

Fig. 1 Distribution of PROMIS Fatigue $7 a, 8 a$, and $4 a$ scores

and 8a were 0.93 ( $95 \%$ CI $0.92,0.95$ ), for $7 \mathrm{a}$ and $4 \mathrm{a}$ were 0.91 ( $95 \%$ CI 0.90 and 0.92 ), and for $8 \mathrm{a}$ and $4 \mathrm{a}$ were 0.98 (95\% CI 0.98, 0.99). As Bland-Altman plots show (Fig. 2), mean differences between scores ranged from -0.56 for the $7 \mathrm{a}$ and $8 \mathrm{a}$ to 0.02 for the $7 \mathrm{a}$ and $4 \mathrm{a}$ with no systematic differences evident. The 95\% limits of agreement were 7.6 to -8.7 for the $7 \mathrm{a}$ and $8 \mathrm{a}$, and were somewhat larger for the $7 \mathrm{a}$ and $4 \mathrm{a}$, and smaller for the $8 \mathrm{a}$ and $4 \mathrm{a}$.

Mean standard errors for the $7 \mathrm{a}, 8 \mathrm{a}$, and 4 a were 2.8 , 2.1, and 2.7. Across CDAI categories, mean SE were inversely related to disease activity level, and ranged from 2.7 to 3.1 for the $7 \mathrm{a}, 1.9$ to 2.4 for the $8 \mathrm{a}$, and 2.7 to 3.0 for the $4 \mathrm{a}$ suggesting adequate reliability at the individual level (i.e., >.90) for all levels of RA disease activity.
Relationship of fatigue with other symptoms associated with RA disease activity

PROMIS-Fatigue SF scores were strongly and negatively associated with Physical Function and Participation (r's - 0.77 to -0.78 ), and moderately-highly and positively correlated with pain, sleep, anxiety, and depression (r's 0.60 to 0.75 ) (Table 4). Associations were strongest between fatigue and other symptoms affected by worsening disease activity (pain, function, participation) [19]. As predicted, fatigue SFs scores were moderately and directly correlated with the patient assessments of disease activity (r's 0.56-0.59), weakly to moderately and directly with tender joint counts, MD assessments of disease activity, and CDAI (r's $0.32-0.50$ ), but only minimally with observable

Table 2 Scores on PROMIS Fatigue short forms and other patient reported outcomes

\begin{tabular}{|c|c|c|c|c|c|c|c|c|c|}
\hline & $\mathrm{N}$ & Mean & SD & Median & $25 \%$ & $75 \%$ & Range & Min & $\operatorname{Max}$ \\
\hline \multicolumn{10}{|l|}{ Fatigue } \\
\hline PROMIS Fatigue 7a & 548 & 58.0 & 11.5 & 58.7 & 50.1 & 66.4 & 53.3 & 29.4 & 82.7 \\
\hline PROMIS Fatigue 8a & 548 & 58.6 & 11.6 & 60.1 & 50.5 & 67.3 & 44.6 & 33.1 & 77.7 \\
\hline PROMIS Fatigue 4a & 546 & 58.0 & 11.6 & 58.9 & 48.6 & 66.6 & 42.1 & 33.7 & 75.8 \\
\hline Rand36 Vitality ${ }^{\mathrm{a}}$ & 388 & 44.1 & 26.3 & 45.0 & 20.0 & 65.0 & 100.0 & 0.0 & 100.0 \\
\hline 7-day fatigue (11 pt. NRS) & 347 & 4.2 & 2.8 & 4.0 & 2.0 & 6.0 & 10.0 & 0.0 & 10.0 \\
\hline Fatigue Likert (1-5) & 546 & 3.3 & 1.3 & 3.5 & 2.0 & 4.0 & 4.0 & 1.0 & 5.0 \\
\hline \multicolumn{10}{|l|}{ Other Measures } \\
\hline PROMIS Physical Function 20a & 546 & 38.7 & 9.4 & 37.3 & 31.8 & 44.1 & 43.7 & 18.8 & 62.5 \\
\hline PROMIS Pain Interference 8a & 548 & 59.3 & 10.2 & 61.0 & 53.3 & 66.9 & 36.3 & 40.7 & 77.0 \\
\hline PROMIS Anxiety 4a & 546 & 52.9 & 10.1 & 53.8 & 40.3 & 60.2 & 41.1 & 40.3 & 81.4 \\
\hline PROMIS Depression 8a & 546 & 51.5 & 10.5 & 51.3 & 38.2 & 59.2 & 42.9 & 38.2 & 81.1 \\
\hline PROMIS Sleep Disturbance 4a & 546 & 53.9 & 10.0 & 54.5 & 48.1 & 61.1 & 41.3 & 32.0 & 73.3 \\
\hline PROMIS Social Participation Ability 8a & 548 & 44.8 & 10.3 & 43.9 & 37.1 & 51.7 & 39.5 & 25.9 & 65.4 \\
\hline Patient Global Disease Activity & 547 & 22.7 & 29.6 & 25.0 & 2.0 & 49.0 & 100.0 & 0.0 & 100.0 \\
\hline
\end{tabular}

${ }^{a}$ Collected only in clinic participants and added after data collection began 
Table 3 Correlations among PROMIS fatigue 7a, 8a, 4a, Rand Vitality and 10-point fatigue scores

\begin{tabular}{|c|c|c|c|c|c|c|}
\hline & & Fatigue $8 a$ & Fatigue $4 a$ & Rand36 & Fatigue NRS & 7d Fatigue \\
\hline \multirow[t]{2}{*}{ Fatigue $7 a$} & $r$ & 0.94 & 0.91 & 0.86 & 0.85 & 0.86 \\
\hline & $\mathrm{N}$ & 548 & 546 & 388 & 347 & 546 \\
\hline \multirow[t]{2}{*}{ Fatigue 8a } & $r$ & & 0.98 & 0.87 & 0.88 & 0.93 \\
\hline & $\mathrm{N}$ & & 549 & 388 & 351 & 546 \\
\hline \multirow[t]{2}{*}{ Fatigue $4 a$} & $r$ & & & 0.86 & 0.88 & 0.96 \\
\hline & $\mathrm{N}$ & & & 387 & 348 & 544 \\
\hline \multirow[t]{2}{*}{ Rand-36 Vitality } & $r$ & & & & 0.81 & 0.82 \\
\hline & $\mathrm{N}$ & & & & 344 & 387 \\
\hline \multirow{2}{*}{$\begin{array}{l}\text { Fatigue NRS } \\
(0-10)\end{array}$} & $r$ & & & & & 0.87 \\
\hline & $\mathrm{N}$ & & & & & 345 \\
\hline
\end{tabular}
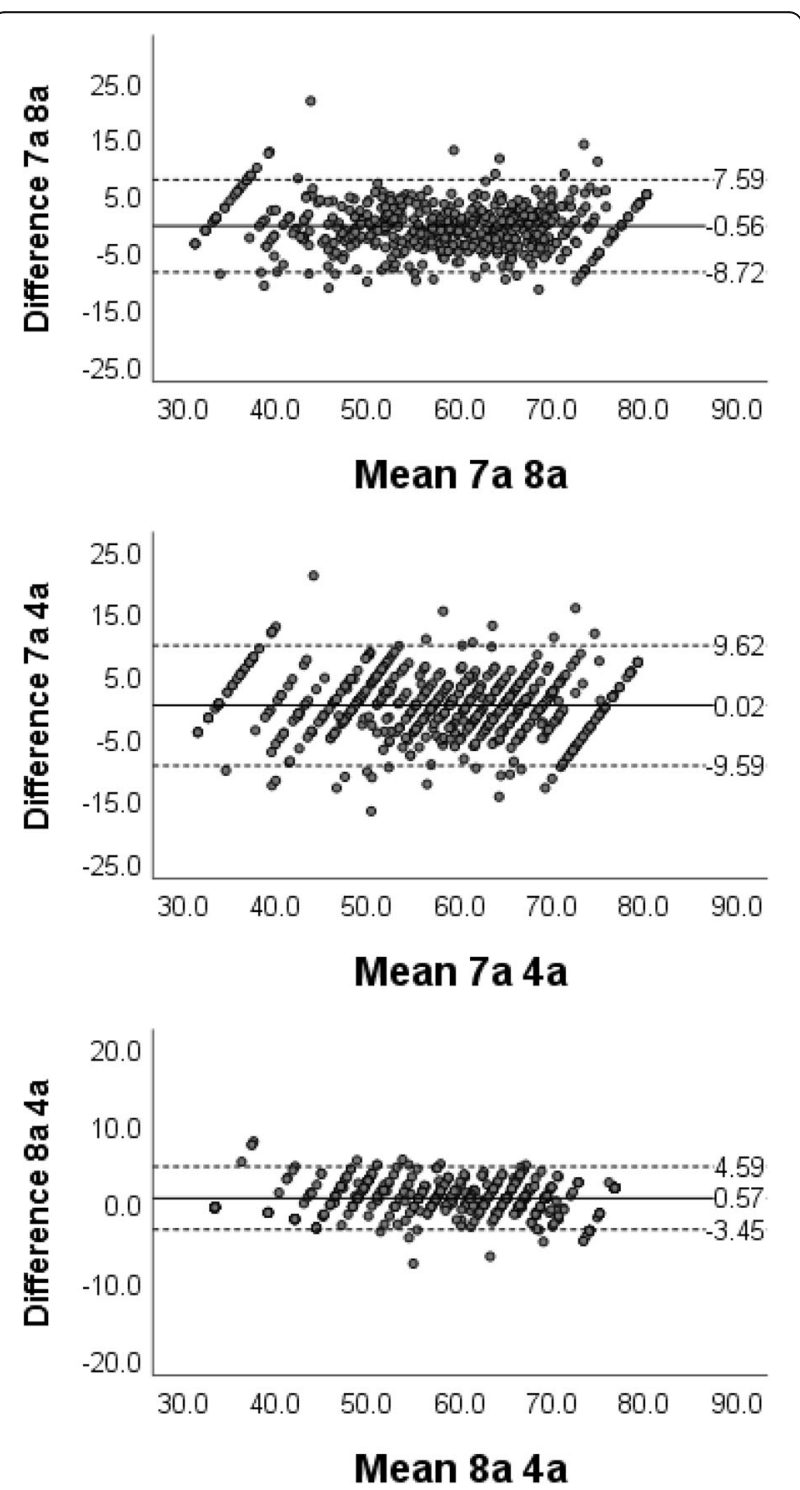

Fig. 2 Bland-Altman plot showing correspondence between scores of PROMIS Fatigue short forms. Lines represent average difference and \pm 1.96 standard deviation of the difference characteristics such as swollen joint counts and laboratory markers of inflammation (r's 0.15-0.22) (Table 4).

Scores on all PROMIS fatigue SFs showed evidence of a dose-response relationship across the fatigue descriptors and CDAI categories (Table 5). The increase in mean PROMIS Fatigue SF scores across categories was at least 1/2-1 SD (i.e., 5-10 points). Within CDAI disease activity levels, considerable variability in fatigue scores was evident as shown in the box-plots in Fig. 3. Among those in remission, very few had fatigue scores $>60$ (1 SD worse than the US population mean); whereas, among those with high disease activity few had fatigue scores $<50$. Within descriptors of fatigue, there was also considerable variability though no patients with high fatigue had scores within the normal range (i.e., 45-55), and few patients reporting no fatigue had scores $>50$.

\section{Discussion}

Fatigue is ubiquitous in active RA, and can vary greatly in severity among individuals, and even within individuals from day-to-day. Among a large, geographically and racially diverse group of people whose RA symptoms varied from none (i.e., remission) to severe, fatigue levels also spanned the full measurement continuum. Scores on the three PROMIS SFs showed evidence of adequate reliability at the group level and correlated highly with each other, with legacy fatigue measures, and with other PROMs that reflect disease activity supporting construct validity. These results are consistent with our earlier work where we evaluated the performance of PROMIS-Fatigue CATs in relation to legacy fatigue scales and other PROMS, and our debriefing studies that showed the Fatigue items were easy to understand and relevant to people with RA [13].

Fatigue in RA has been hypothesized to result from several things including the greater physiological burden associated with high systemic inflammatory activity to increased difficulty moving due to swollen, painful joints. However, living with a chronic disease is also associated with greater depression and anxiety, sleep disturbance, 
Table 4 Correlation of PROMIS fatigue short forms with other PROMIS measures and other clinical disease indicators of RA

\begin{tabular}{|c|c|c|c|c|c|c|c|c|c|c|c|c|c|c|}
\hline \multicolumn{2}{|c|}{$\begin{array}{l}\text { PROMIS } \\
\text { Fatigue }\end{array}$} & \multirow{2}{*}{$\begin{array}{l}\text { Physical } \\
\text { Function } \\
-0.78\end{array}$} & \multirow{2}{*}{$\begin{array}{l}\text { Participation } \\
-0.81\end{array}$} & \multirow{2}{*}{$\begin{array}{l}\begin{array}{l}\text { Pain } \\
\text { Interference }\end{array} \\
0.78\end{array}$} & \multirow{2}{*}{$\begin{array}{l}\begin{array}{l}\text { Sleep } \\
\text { Disturbance }\end{array} \\
0.65\end{array}$} & \multirow{2}{*}{$\begin{array}{l}\text { Anxiety } \\
0.63\end{array}$} & \multirow{2}{*}{$\begin{array}{l}\text { Depression } \\
0.67\end{array}$} & \multirow{2}{*}{$\begin{array}{l}\text { TJC28 } \\
0.34\end{array}$} & \multirow{2}{*}{$\begin{array}{l}\text { SJC28 } \\
0.19\end{array}$} & \multirow{2}{*}{$\begin{array}{c}\text { MD } \\
0.32\end{array}$} & \multirow{2}{*}{$\begin{array}{l}\text { Patient } \\
0.59\end{array}$} & \multirow{2}{*}{$\begin{array}{l}\text { CDAl } \\
0.47\end{array}$} & \multirow{2}{*}{$\begin{array}{l}\text { ESR } \\
0.21^{*}\end{array}$} & \multirow{2}{*}{$\begin{array}{l}\mathrm{CRP}(\mathrm{mg} / \mathrm{L}) \\
0.17^{*}\end{array}$} \\
\hline $7 a$ & $r$ & & & & & & & & & & & & & \\
\hline & $N$ & 546 & 548 & 548 & 546 & 546 & 546 & 345 & 346 & 343 & 547 & 340 & 219 & 254 \\
\hline \multirow[t]{2}{*}{$8 a$} & $r$ & -0.78 & -0.78 & 0.75 & 0.63 & 0.60 & 0.64 & 0.37 & 0.21 & 0.34 & 0.57 & 0.50 & 0.23 & $0.15^{* *}$ \\
\hline & $N$ & 546 & 548 & 548 & 546 & 546 & 546 & 345 & 346 & 343 & 547 & 340 & 219 & 254 \\
\hline \multirow[t]{2}{*}{$4 a$} & $r$ & -0.77 & -0.77 & 0.75 & 0.65 & 0.59 & 0.63 & 0.37 & 0.22 & 0.35 & 0.56 & 0.50 & 0.22 & $0.15^{* *}$ \\
\hline & $\mathrm{N}$ & 546 & 546 & 546 & 546 & 546 & 546 & 343 & 344 & 341 & 545 & 338 & 219 & 252 \\
\hline
\end{tabular}

All $p<0.001$ except ${ }^{*} p<.005$ and ${ }^{* *} p<.02$

and challenges maintaining participation in social roles and activities - each of which may also contribute to fatigue. Many fatigue measures query different aspects of fatigue ranging from simple global severity rating scales to multidimensional measures that ask about different ways people experience fatigue (e.g., cognitive difficulties, muscle weakness) to how it impacts daily activities (e.g., participation, work productivity, activities of daily living). Existing fatigue measures that are widely used vary in scope, length, domains, and statistical properties. PROMIS Fatigue SFs ask about the intensity of fatigue and its impact on day-to-day function. Our results suggest that each of the SF measures can discriminate among levels of fatigue across the full range of RA disease activity. PROMIS developers showed that Fatigue SF scores correlate highly ( $r$ 's $>0.95$ ) with scores derived from CATs (see Fatigue Scoring Guide at healthmeasur es.net) using the full item bank, with greatest precision of the SFs in the range from roughly 48 to 70 , or in those with RA who describe their fatigue as ranging from none to severe.

Although it has been widely reported that fatigue increases with disease activity, additional mechanisms through which fatigue contributes to disability and suboptimal wellbeing associated with RA are not well understood. The Fatigue SF scores correlated most with other measures that are directly impacted by RA disease activity, including pain, function, and social participation (r's $>0.7$ ). Notably, though this sample included individuals with RA disease activity ranging from remission (i.e., no evidence of active disease) to high, mood and sleep disturbance were within the normal range in all but those with the highest levels of disease activity (data not shown), as we reported in an earlier study (11).

PROMIS-Fatigue SFs can quantify fatigue across the full continuum of RA disease activity. Scores increased significantly across CDAI levels by $\geq 0.5$ SD ( 5 units), an amount that is widely recognized as clinically meaningful [20]. There was also evidence of dose-response relationships in SF scores as patients described the intensity of their fatigue worsening from 'none' to 'severe'.

Mean scores were similar among SFs as shown by high ICCs, and on average differed by $<1$ point even though the 7- and 8-item forms contain different items. These results from larger, more diverse samples of RA patients are similar to those we have previously obtained using PROMIS-Fatigue CATs [12]. However, the $95 \%$ limits of agreement between the $7 \mathrm{a}$ and $8 \mathrm{a}$ showed that there were often important differences at the individual level of up to 8-9 points (i.e., nearly $1 \mathrm{SD}$ ) which could result in misclassification.

The option to administer different subsets of test items via CAT or paper-based SFs reflects an important strength of using IRT-derived measures. While CATs

Table 5 Mean PROMIS fatigue scores by patient descriptors of symptom severity and indicators of RA disease activity

\begin{tabular}{|c|c|c|c|c|c|c|c|c|c|c|c|c|}
\hline & $\mathrm{N}$ & Mean & SD & $\mathrm{N}$ & Mean & SD & $\mathrm{N}$ & Mean & SD & $N$ & Mean & $\overline{S D}$ \\
\hline Descriptors & \multicolumn{3}{|c|}{ None } & \multicolumn{3}{|l|}{ Mild } & \multicolumn{3}{|c|}{ Moderate } & \multicolumn{3}{|c|}{ Severe } \\
\hline Fatigue 7a & 47 & 38.8 & 6.4 & 135 & 48.6 & 6.4 & 127 & 59.6 & 6.1 & 39 & 69.7 & 4.9 \\
\hline Fatigue 8a & 47 & 36.3 & 5.1 & 135 & 49.2 & 5.3 & 127 & 61.1 & 4.9 & 39 & 71.4 & 4.7 \\
\hline Fatigue 4a & 47 & 36.8 & 5.0 & 135 & 48.4 & 5.5 & 125 & 60.4 & 5.1 & 39 & 71.1 & 4.6 \\
\hline CDAl & \multicolumn{3}{|c|}{ Remission } & \multicolumn{3}{|l|}{ Low } & \multicolumn{3}{|c|}{ Moderate } & \multicolumn{3}{|c|}{ High } \\
\hline Fatigue 7a & 80 & 46.3 & 8.4 & 132 & 52.0 & 9.6 & 94 & 58.4 & 10.7 & 34 & 62.7 & 8.4 \\
\hline Fatigue 8a & 80 & 46.7 & 8.8 & 132 & 52.5 & 9.7 & 94 & 59.3 & 11.2 & 34 & 64.5 & 8.4 \\
\hline Fatigue $4 a$ & 80 & 46.3 & 8.7 & 131 & 51.9 & 9.8 & 93 & 58.6 & 11.0 & 34 & 63.9 & 8.5 \\
\hline
\end{tabular}

Mean values in the same row are significantly different from each other at $p<.05$ 


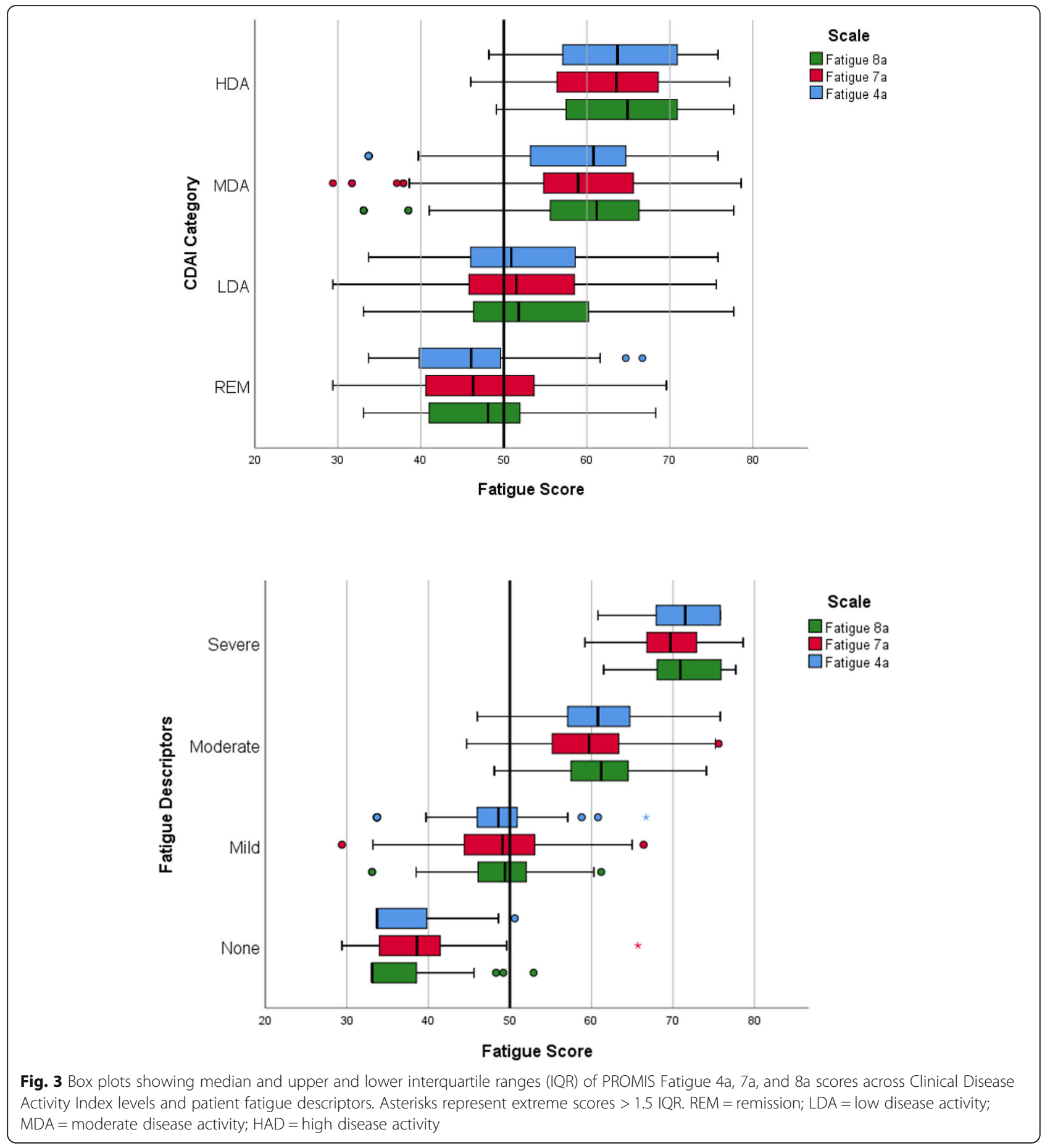

result in better precision and efficiency, our results increase confidence that SFs containing 4-, 7-, or 8-items offer an acceptable alternative to measuring fatigue in RA when CAT administration of measures is not feasible. Notably, the 4-item version is contained in the PROMIS-29 Profile. The opportunity to choose from among SFs available with differing lengths is also a strength of PROMIS and IRT approaches to measurement optimization and may appeal to investigators who are hesitant to stop using existing familiar fatigue measures with which they are more familiar (and from which some PROMIS items may have been drawn).

Other benefits to using PROMIS SFs to measure fatigue include the reduced item number compared to some other legacy measures (e.g., FACIT-Fatigue, BRAF), thus reducing respondent burden. The availability of US general 
population norms facilitates comparisons of scores with those of age and sex-matched individuals. Finally, PROMIS-Fatigue SFs have been widely translated (7a-25 languages, 8a-29 languages, source: healthmeasures.net, accessed April 4, 2018), with additional efforts ongoing facilitating their use in multi-lingual populations and multinational studies.

Strengths of the study are the large diverse sample with a broad range of socio-demographic and RA characteristics. Our two-step screening approach increases confidence that the online sample included people with inflammatory arthritis. Among clinic participants, we triangulated fatigue scores with observations from clinicians and laboratory data. There are also limitations. Participants in the online sample had higher levels of reported symptoms and were self-selected for participation in the online survey, perhaps limiting generalizability of their results. However, in combination with the clinic-based sample with an average lower levels of symptoms we covered the range of disease activity across the studies. Data were drawn from the baseline visit of patients with established RA who were receiving care at tertiary arthritis clinics and enrolled in an observational trial. We recognize that comorbidities common to people with RA (e.g., diabetes, fibromyalgia, obstructive sleep apnea) could influence fatigue. However, our large sample size drawn from multiple sources likely helps overcome these concerns. As we used cross-sectional data, we could not examine responsiveness, and change in fatigue in relation to RA treatments or other intervention remain topics for future investigation. We did not evaluate structural validity; others have published results of extensive validity test of PROMIS Fatigue items across chronic diseases [9, 10, 21]. The evidence presented in our study came from IRT-based scoring of PROMIS scores through the Assessment Center rather than look-up tables. Finally, we examined performance of PROMIS Fatigue SFs in relation to a limited number of legacy fatigue measures.

\section{Conclusions}

These results provide robust evidence supporting the construct validity of the three versions of PROMIS-Fatigue SFs that include 4, 7, and 8 items. Though CATs offer greater precision, the SFs can efficiently measure fatigue across the spectrum of RA disease activity in diverse groups of individuals and justify their consideration as one of the important patient-centered assessments that reflect disease control and treatment efficacy. Precise measures of fatigue using these PROMIS SFs can quantify fatigue associated with RA disease activity and its impact. Ultimately, these measures of fatigue can contribute to patient-centered discussions to help match individuals with optimal therapies based on health considerations that matter most to them.

\section{Acknowledgements}

The authors would like to thank research teams at Johns Hopkins, Hospital for Special Surgery, and University of Alabama at Birmingham for their assistance (Michelle Jones, Bernadette Johnson, Kathleen Andersen, Jessica Ashley) and the rheumatologists and trainees who referred patients for participation in the studies. We gratefully acknowledge assistance from Global Healthy Living Foundation for access to an online arthritis patient community through CreakyJoints.org and technical support from David Curtis. We thank members of our external advisory group to this project, including our patient research partners Ms. Amye Leong and Ms. Anne Lyddiatt, in addition to Dr. James Witter, Dr. April Naegeli, and Victoria Ruffing RN-BC (Rheum).

\section{Funding}

This research was supported by an award from the Patient Centered Outcomes Research Institute (PCORI, ME-1402-10818), the Rheumatic Diseases Research Core Center (NIH P30-AR070254 Cores A and B, NIH P30-AR053503 Cores A and D), a contract from the Critical Pathway Institute, the Camille Julia Morgan Arthritis Research and Education Fund, the Scherr Family Fund and Adam and Joanne Rogers. All statements in this report including the conclusions are those of the authors and do not reflect the opinions of PCORI, its Board of Governors, or its Methodology Committee, or of the National Institutes of Health or the National Institutes of Arthritis Musculoskeletal and Skin Diseases.

Availability of data and materials

Please contact author for data requests.

\section{Authors' contributions}

COB and SJB conceptualized and designed the study, collected, analyzed, and interpreted data, and drafted and revised the manuscript for publication. $J R C, V P B, A K G, W B N, A M O, A B$ contributed to study design and operationalization, data collection, interpretation of results, and manuscript revisions. $\mathrm{AL}$ and $\mathrm{AL}$ contributed to study design, interpretation of results, and manuscript revisions. Authors are accountable for all aspects of the work. All authors read and approved the final manuscript.

\section{Ethics approval and consent to participate}

This research was performed in accordance with the Declaration of Helsink and was approved by review boards at Johns Hopkins (IRB00059765 and 0059930) with additional approval at University of Alabama at Birmingham (X150722003) and The Hospital for Special Surgery (2015-238). Written informed consent was obtained from all participants.

Consent for publication

Not applicable.

Competing interests

The authors declare that they have no competing interests.

\section{Publisher's Note}

Springer Nature remains neutral with regard to jurisdictional claims in published maps and institutional affiliations.

\footnotetext{
Author details

${ }^{1}$ Johns Hopkins Medicine, Division of Rheumatology, Mason F Lord Center Tower, 5200 Eastern Ave \#434A, Baltimore, MD 21224, USA. ${ }^{2}$ Johns Hopkins Medicine, Division of Rheumatology, Mason F Lord Tower, 5200 Eastern. Avenue, Rm 4100, Baltimore, MD 21224, USA. ${ }^{3}$ Hospital for Special Surgery, Weill Cornell Medical College, 525 East 71st St, 7th floor, New York, NY 10021, USA. ${ }^{4}$ Division of Rheumatology, University of Alabama at Birmingham, Birmingham, AL, USA. ${ }^{5}$ Healthy Motivation, Santa Barbara, CA, USA. ${ }^{6}$ Patient Partners, Ingersoll, ON, Canada. ${ }^{7}$ Global Healthy Living Foundation, Upper Nyack, NY, USA. ${ }^{8}$ Center for Health Outcomes Research, McGill University, 5252 de Maisonneuve West, \#3D-57, Montreal, QC H4A 3S5, Canada.
} 
Received: 5 June 2018 Accepted: 12 February 2019

Published online: 21 February 2019

\section{References}

1. Kirwan, J. R., \& Hewlett, S. (2007). Patient perspective: Reasons and methods for measuring fatigue in rheumatoid arthritis. J Rheumatol, 34, 1171-1173.

2. Hewlett, S., Cockshott, Z., Byron, M., Kitchen, K., Tipler, S., Pope, D., \& Hehir, M. (2005). Patients' perceptions of fatigue in rheumatoid arthritis: Overwhelming, uncontrollable, ignored. Arthritis Rheum, 53, 697-702.

3. Katz, P. (2017). Fatigue in rheumatoid arthritis. Curr Rheumatol Rep, 19, 25.

4. Sanderson, T., Morris, M., Calnan, M., Richards, P., \& Hewlett, S. (2010). Patient perspective of measuring treatment efficacy: The rheumatoid arthritis patient priorities for pharmacologic interventions outcomes. Arthritis Care Res (Hoboken), 62, 647-656

5. Kirwan, J. R., Minnock, P., Adebajo, A., Bresnihan, B., Choy, E., de Wit, M., Hazes, M., Richards, P., Saag, K., Suarez-Almazor, M., et al. (2007). Patient perspective: Fatigue as a recommended patient centered outcome measure in rheumatoid arthritis. J Rheumatol, 34, 1174-1177.

6. Felson, D. T., Smolen, J. S., Wells, G., Zhang, B., van Tuyl, L. H., Funovits, J., Aletaha, D., Allaart, C. F., Bathon, J., Bombardieri, S., et al. (2011). American College of Rheumatology/European league against rheumatism provisional definition of remission in rheumatoid arthritis for clinical trials. Arthritis Rheum, 63, 573-586.

7. Hewlett, S., Dures, E., \& Almeida, C. (2011). Measures of fatique: Bristol rheumatoid arthritis fatigue multi-dimensional questionnaire (BRAF MDQ), Bristol rheumatoid arthritis fatigue numerical rating scales (BRAF NRS) for severity, effect, and coping, Chalder fatigue questionnaire (CFQ), checklist Individual Strength (CIS20R and CIS8R), Fatigue Severity Scale (FSS), Functional Assessment Chronic Illness Therapy (Fatigue) (FACIT-F), MultiDimensional Assessment of Fatigue (MAF), Multi-Dimensional Fatigue Inventory (MFI), Pediatric Quality Of Life (PedsQL) Multi-Dimensional Fatigue Scale, Profile of Fatigue (ProF), Short Form 36 Vitality Subscale (SF-36 VT), and Visual Analog Scales (VAS). Arthritis Care Res, 63(Suppl 11), S263-S286.

8. Aletaha, D., Landewe, R., Karonitsch, T., Bathon, J., Boers, M., Bombardier, C., Bombardieri, S., Choi, H., Combe, B., Dougados, M., et al. (2008). Reporting disease activity in clinical trials of patients with rheumatoid arthritis: EULAR/ ACR collaborative recommendations. Arthritis Rheum, 59, 1371-1377.

9. Cella, D., Lai, J. S., Jensen, S. E., Christodoulou, C., Junghaenel, D. U., Reeve, B. B., \& Stone, A. A. (2016). PROMIS fatigue item Bank had clinical validity across diverse chronic conditions. J Clin Epidemiol, 73, 128-134.

10. Cook, K. F., Jensen, S. E., Schalet, B. D., Beaumont, J. L., Amtmann, D., Czajkowski, S., Dewalt, D. A., Fries, J. F., Pilkonis, P. A., Reeve, B. B., et al. (2016). PROMIS measures of pain, fatigue, negative affect, physical function, and social function demonstrated clinical validity across a range of chronic conditions. J Clin Epidemiol, 73, 89-102.

11. Lai, J. S., Cella, D., Choi, S., Junghaenel, D. U., Christodoulou, C., Gershon, R., \& Stone, A. (2011). How item banks and their application can influence measurement practice in rehabilitation medicine: A PROMIS fatigue item bank example. Arch Phys Med Rehabil, 92, S20-S27.

12. Bartlett, S. J., Orbai, A. M., Duncan, T., DeLeon, E., Ruffing, V., Clegg-Smith, K., \& Bingham, C. O., 3rd. (2015). Reliability and validity of selected PROMIS measures in people with rheumatoid arthritis. PLoS One, 10, e0138543.

13. Bartlett, S. J, Gutierrez, A. K., Butanis, A., Bykerk, V. P., Curtis, J., R., Ginsberg, S., Leong, A., L., Lyddiatt, A., Nowell, W., B., Orbai, A., M., Smith, K., C., Bingham, C., O. 3rd. (2018) Combining online and in-person methods to evaluate the content validity of promis fatigue short forms in rheumatoid arthritis. Qual Life Res, 27 (9):2443-2451. https://doi.org/10.1007/s11136-018-1880-x. Epub 2018 May 24. PMID: 29797175

14. Karlson, E. W., Sanchez-Guerrero, J., Wright, E. A., Lew, R. A., Daltroy, L. H., Katz, J. N., \& Liang, M. H. (1995). A connective tissue disease screening questionnaire for population studies. Ann Epidemiol, 5, 297-302.

15. Cella, D., Riley, W., Stone, A., Rothrock, N., Reeve, B., Yount, S., Amtmann, D., Bode, R., Buysse, D., Choi, S., et al. (2010). The patient-reported outcomes measurement information system (PROMIS) developed and tested its first wave of adult self-reported health outcome item banks: 2005-2008. J Clin Epidemiol, 63, 1179-1194.

16. Hays, R. D., Sherbourne, C. D. \& Mazel, R. M. (1993). The RAND 36-item health survey 1.0. Health Econ, 2, 217-227.

17. Nunnally, J. C., \& Bernstein, I. H. (1994). Psychometric Theory (3rd ed.). New York: McGraw-Hill.
18. McHorney, C. A., \& Tarlov, A. R. (1995). Individual-patient monitoring in clinical practice: Are available health status surveys adequate? Qual Life Res, 4, 293-307.

19. Bartlett, S. J., Hewlett, S., Bingham, C. O., 3rd, Woodworth, T. G., Alten, R. Pohl, C., Choy, E. H., Sanderson, T., Boonen, A., Bykerk, V., et al. (2012). Identifying core domains to assess flare in rheumatoid arthritis: An OMERACT international patient and provider combined Delphi consensus. Ann Rheum Dis, 71, 1855-1860.

20. Lai, J. S., Cella, D., Yanez, B., \& Stone, A. (2014). Linking fatigue measures on a common reporting metric. J Pain Symptom Manag, 48, 639-648.

21. Jensen, R. E., Moinpour, C. M., Potosky, A. L., Lobo, T., Hahn, E. A., Hays, R. D., Cella, D., Smith, A. W., Wu, X. C., Keegan, T. H., et al. (2017). Responsiveness of 8 patient-reported outcomes measurement information system (PROMIS) measures in a large, community-based cancer study cohort. Cancer, 123, 327-335.

\section{Submit your manuscript to a SpringerOpen ${ }^{\circ}$ journal and benefit from:}

- Convenient online submission

- Rigorous peer review

- Open access: articles freely available online

- High visibility within the field

- Retaining the copyright to your article

Submit your next manuscript at $\boldsymbol{\nabla}$ springeropen.com 